\title{
Theoretical design of innovative cold formed steel beam sections
}

\author{
M. Adil Dar ${ }^{1}$, Deepankar K. Ashish ${ }^{2}$, A. R. Dar ${ }^{3}$ \\ ${ }^{1} P G$ Research Scholar, Structural Engineering, Kurukshetra University, Haryana, India \\ ${ }^{2}$ Ph.D. Scholar, Structural Engineering, PEC University of Technology, Chandigarh, India \\ ${ }^{3}$ Professor \& Head, Civil Engineering, National Institute of Technology, Srinagar, J\&K, India \\ *Corresponding author E-mail: dar.adil89@gmail.com
}

Copyright $\odot 2015$ M. Adil Dar et al. This is an open access article distributed under the Creative Commons Attribution License, which permits unrestricted use, distribution, and reproduction in any medium, provided the original work is properly cited.

\begin{abstract}
In today's world, the construction industry both structural and non-structural elements are fabricated from thin gauges of steel sheets. These thin walled sections are being used as columns, beams, joists, studs, floor decking, built-up sections and other components for lightly loaded structures. Unlike hot rolled sections, the design of Cold-Formed Steel (CFS) section for beam is predominantly controlled by various buckling modes of failure, thereby drastically reducing their load carrying capacity. Hence there is an urgent need in the CFS industry to look beyond the conventional CFS beam sections and investigate newly proposed innovative CFS beam sections, which seem to prove structurally much more efficient. Prior to any experimental investigation of innovative beam sections, there is a need to carry out theoretical design using some of the most appropriate available methods applicable to the case under consideration. This paper focuses on such theoretical designs for various innovative sections using available analytical design tools together with appropriate codal guidelines.
\end{abstract}

Keywords: Analytical Tools; Buckling; Codal Guidelines; Innovative Sectional Profiles; Lightly Loaded Structures.

\section{Introduction}

Cold Formed Steel (CFS) members are widely employed in steel construction because of their lighter weight and higher economy than traditional hot-rolled sections. The use of CFS structures has increased rapidly in recent years due to significant improvements in manufacturing technologies. CFS members are made from steel sheets and are formed into different shapes either through press-braking sheared form sheets or coils or more commonly, by rolling done at room temperature. CFS sections are typically thin-walled with a thickness ranging from $0.4 \mathrm{~mm}$ to $6.5 \mathrm{~mm}$ [1]. The most commonly used shapes of CFS member are lipped channel, Z and C shapes, hat and tubular sections [2] \& [3] as shown in Fig. 1. The CFS sections offer one of the highest loads capacity-to-weight ratios among the various structural components currently in the market. It also offers economy in production, transportation and handling. CFS sections with edge stiffened flanges have three types buckling specifically local buckling [18], distortional buckling and Euler's buckling (flexural or flexural-torsional), generally called as global buckling [4] \& [5]. Local buckling is normally defined as a mode that involves deformation of some or all of the individual plate elements forming a cross section. Distortional buckling involves deformations of the junctions between plate elements. Several studies have been conducted on cold formed steel buckling modes [6-13] by various authors.
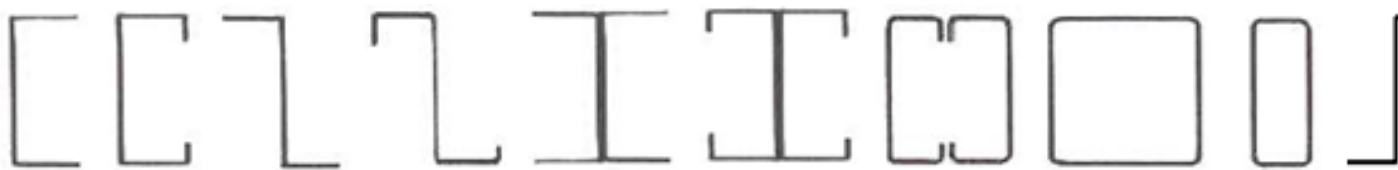

Fig. 1: Conventional Light Gauge Sectional Profiles [14] 


\section{Justifications of sectional profiles chosen}

Steel is the only choice as an ideal construction material for most of the challenging structural engineering problems like tall structures, long span bridges etc. Steel is also, an ideal reinforcement for plain concrete (overcoming its inherent undesirable property of low tensile strength) thus making it one of the most commonly used material (RCC) world over. In view of the limited steel resources and the key role played by steel in the modern construction industry, there is an urgent need to ensure the most economic utilization of this precious material for benefit of mankind in future. It is worth using hot rolled steel sections in key elements like columns, long span beams etc. However, using hot rolled steel sections in moderate to lightly loaded members proved to be highly uneconomical because such sections remain underutilized. To overcome this problem encountered with hot rolled sections, CFS sections provides the best solution for such moderate/lightly loaded sections. Moreover, a combination of hot rolled steel sections for primary members and CFS sections for secondary members will not only result in safe building structures but with desired economy.

The main problem encountered in the CFS is its premature stability failure, hence drastically reducing their true load carrying capacity potential. This stability failure occurs well before the material has reached close to its yield strength (which leaves the section underutilized to its full capacity) [15], hence the need of the hour is to come up with new innovative sectional profile and stiffening arrangements which would together help either in delaying or completely eliminating the stability failure so, that the section is utilized to its full load carrying capacity [16].

As we all know in the conventional hot-rolled steel, the section which is most efficient under flexure is I- section. Thus for better comparison, some similar section has to be proposed. But forming I- section in light gauge steel can only be done by connecting two-channel type or similar sections back to back.

But channel section without edge stiffener would again show local buckling; hence the section had to be stiffened using edge stiffeners/ lip stiffeners. But this may show torsional failure (due to in-evitable eccentricity in loading) hence sectional profile 'A' as shown in the Fig. 2 was proposed but this showed no improvement in the load carrying capacity. To increase the load carrying capacity to some more extent the section modulus had to be increased, which was achieved by proposing sectional profile ' $B$ ' as shown in the Fig. 2. But the problem with sectional profile ' $A$ ' and ' $B$ ' is that if provided with stiffening arrangement, the acute angle corners will be left un-attended, thus the sectional profile ' $\mathrm{C}$ ' was proposed with $90^{\circ}$ corner in which angle section can be easily adopted as an efficient stiffening element.

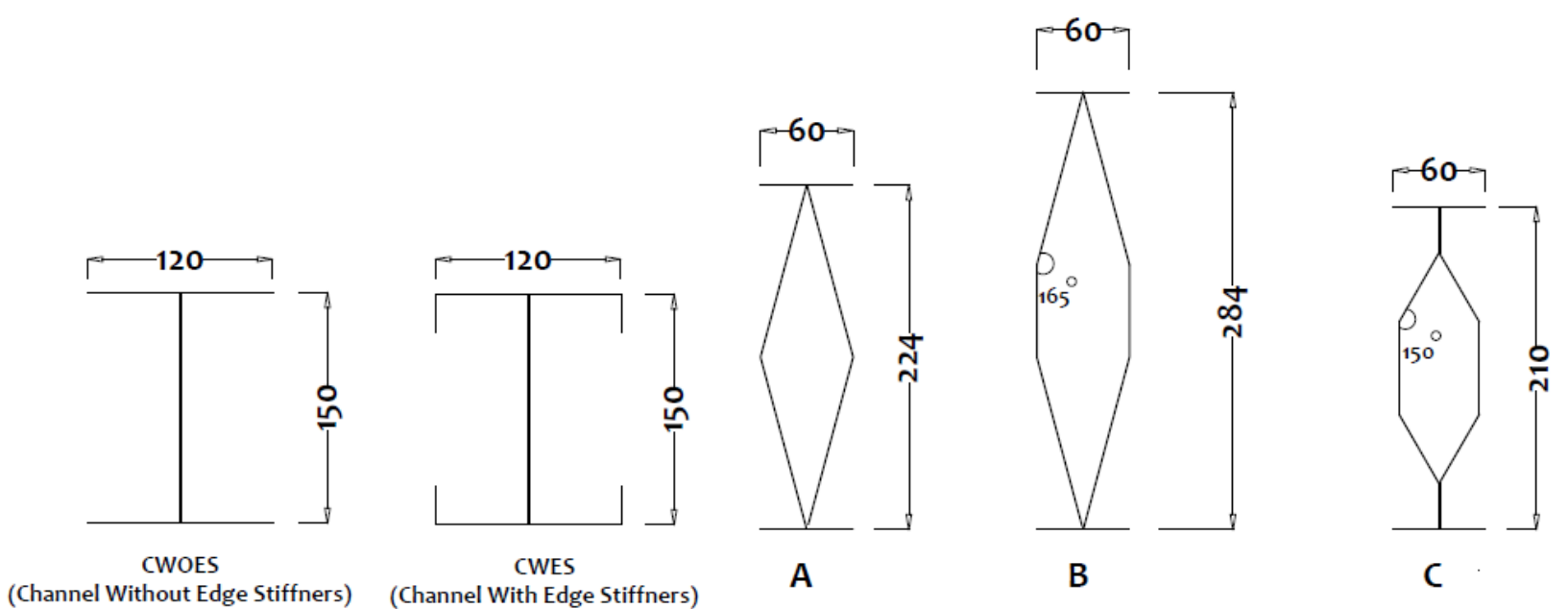

Fig. 2: Proposed Sectional Profiles.

\section{Objectives of theoretical design}

- To shortlist the efficient sections through analysis for experimental validation.

- To validate the predicted behavior based on theoretical design by experimental results

- To evaluate the efficiency of various stiffening measures.

- To identify the weak zones in the innovative sections.

- $\quad$ To identify the modes of premature buckling failure and appropriate remedial measures.

\section{Simplified and cost effective fabrication of the sectional profiles}

Making sections out of single strip will no doubt be structurally efficient but the fabrication process of cold forming and electric welding will make the manufacturing process complicated and expensive. Therefore the method of formation of the proposed sectional profiles should be simple. The innovative sections were formed by joining suitable channel sections back to back as shown in Fig. 3. 


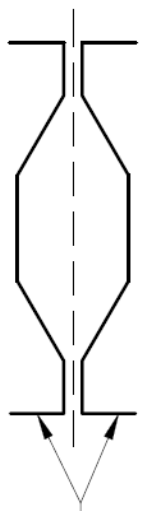

\section{Channel Sections connected back to back}

Fig. 3: Fabrication of Innovative Sections

\section{Analysis and design of innovative sections for load carrying capacity}

The analysis and design of innovative sections was carried out using I.S. 811 (1987) Indian Standard Specification for Cold- Formed Light Gauge Structural Steel Sections, Bureau of Indian Standards. Basic design stresses (f) were quantified followed by allowable compressive stress $\left(\mathrm{f}_{\mathrm{c}}\right)$ calculation. After this effective width (b) and moment of inertia (I) is determined. Lastly flexural formula is used for Moment of resistance calculation which lead to design load determination.

\subsection{Analysis of beam section (CWOES) for moment carrying capacity}

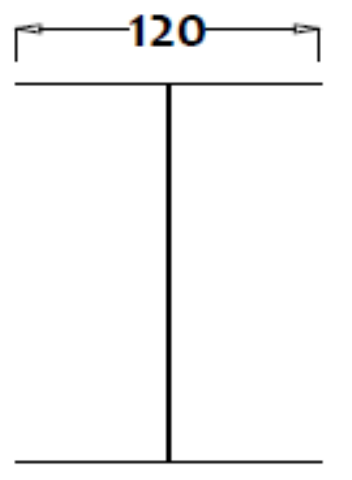

CWOES

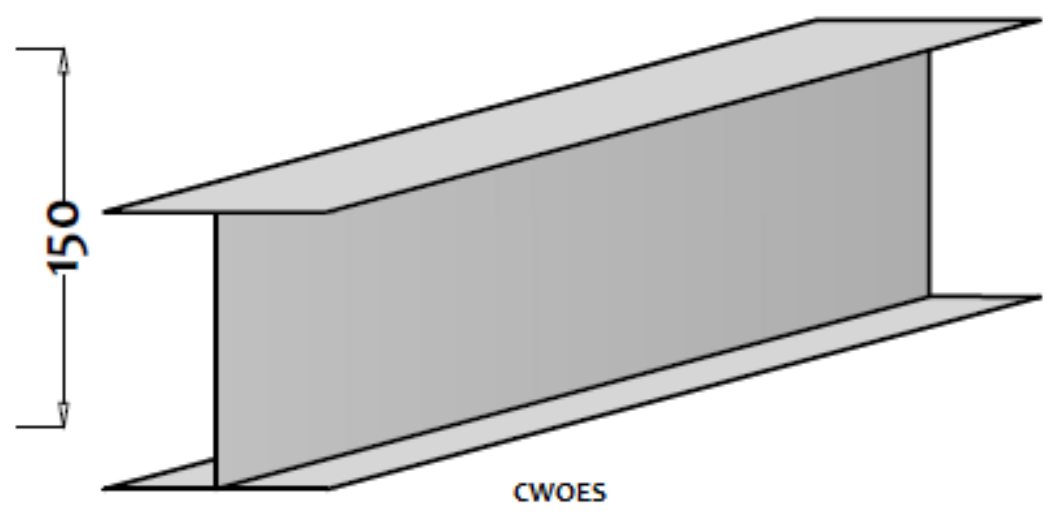

Fig. 4: Channel without Edge Stiffener

Basic design stress $\mathrm{f}=0.6 \mathrm{f}_{\mathrm{y}}=0.6 * 250=150 \mathrm{~N} / \mathrm{mm}^{2}$ (for stiffened compression elements) but according to clause 6.2 of

[17].

Allowable compression stress in unstiffened element is (in S.I. units)

For

$\frac{\mathrm{w}}{\mathrm{t}} \leq \frac{165}{\sqrt{\mathrm{f}_{\mathrm{y}}}}$

$f_{c}=0.6 \sqrt{f_{y}}$

For

$\frac{375}{\sqrt{f_{y}}}>\frac{w}{t}>\frac{165}{\sqrt{f_{y}}}$ 
$f_{c=} f_{y}\left[0.767-10^{\wedge}-3\left(\frac{w}{t}\right) \sqrt{ } f_{y}\right]$

For

$25>\mathrm{w} / \mathrm{t}>375 / \sqrt{\mathrm{f}_{\mathrm{y}}}$

$\mathrm{f}_{\mathrm{c}}=54200 /\left(\frac{\mathrm{w}}{\mathrm{t}}\right)^{2}$

For

$60>w / t>25$

$\mathrm{f}_{\mathrm{c}}=134-1.93\left(\frac{\mathrm{w}}{\mathrm{t}}\right)$

Where $w=$ width of the flange;

$\mathrm{t}=$ thickness of the flange,

$\mathrm{f}_{\mathrm{y}}=$ yield stress \&

$\mathrm{f}_{\mathrm{c}}=$ allowable compressive stress.

Hence from the above clause

$\frac{\mathbf{6 0}}{2} \leq \frac{\mathbf{1 6 5}}{\sqrt{250}}=30>10.43$

$60>\mathrm{w} / \mathrm{t}>25$

$\mathrm{f}_{\mathrm{c}}=134-1.93\left(\frac{\mathrm{w}}{\mathrm{t}}\right)$

Hence allowable compressive stress is given by

$\mathrm{f}_{\mathrm{c}}=134-1.93\left(\frac{\mathrm{w}}{\mathrm{t}}\right)$

$\mathrm{f}_{\mathrm{c}}=134-1.93\left(\frac{30}{2}\right)=76.1 \mathrm{~N} / \mathrm{mm}^{2}$

To find effective design width

$\left(\frac{w}{t}\right) \lim =\frac{446}{\sqrt{f}}$

(Clause 5.2.1.1 of [17])

Where $\mathrm{w}=$ width of the flange; $\mathrm{t}=$ thickness of flange.

$\left(\frac{w}{t}\right) \lim =\frac{446}{\sqrt{150}}=39.268$

$\mathrm{w} / \mathrm{t}=60 / 2=30<39.268$

Hence $b=w=60 \mathrm{~mm}$.

Sectional properties.

$\mathrm{I}_{\mathrm{xx}}=1.9125 \times 10^{6} \mathrm{~mm}^{4}$

$M=\frac{I x x}{y} \times f_{y}$

Where $\mathrm{I}_{\mathrm{xx}}=$ moment of inertia of section horizontal axis passing through centroid of the section. $\mathrm{Y}=$ distance of extreme fiber in compression from neutral axis.

$\mathrm{M}=\frac{1.9125 * 10^{\wedge} 6}{75} \times 76.1=1.94 \mathrm{kN}-\mathrm{m}$ 
For beam under single point load $\mathrm{p}=\frac{4 \mathrm{M}}{\mathrm{l}}$

$\mathrm{p}=\frac{4 * 1.94}{1}=7.76 \mathrm{kN}=0.7 \mathrm{~T}$

\subsection{Analysis of beam section (CWES) for moment carrying capacity}

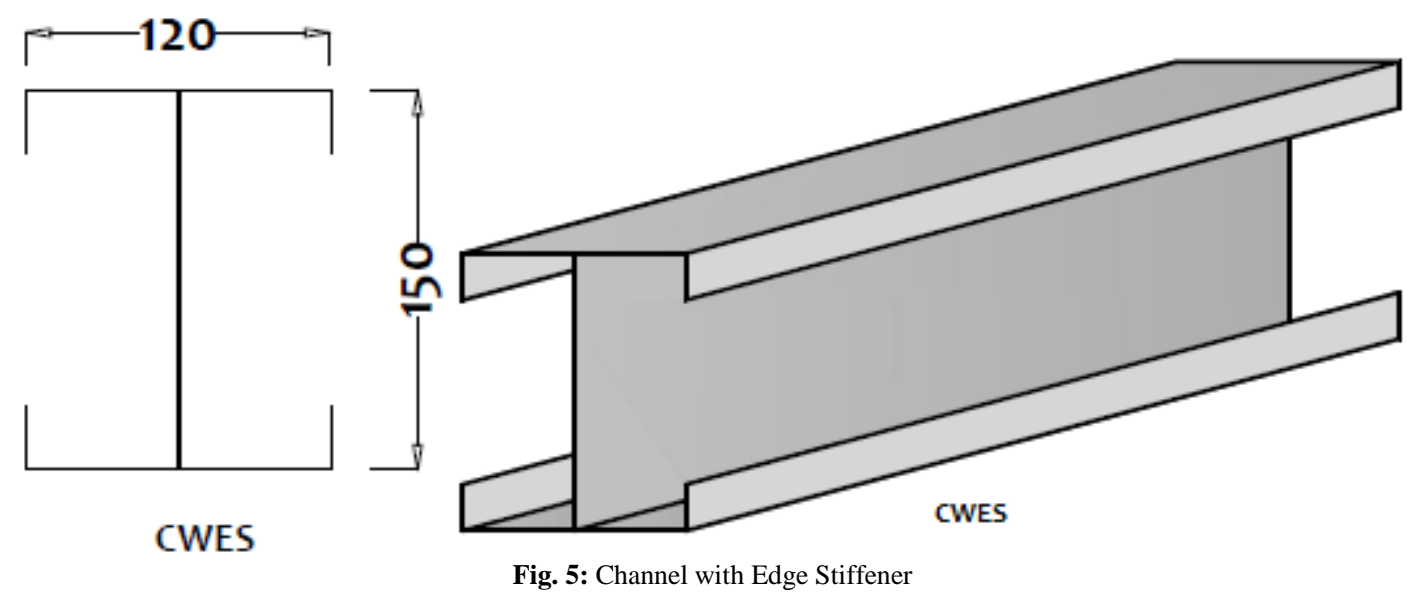

Basic design stress $\mathrm{f}=0.6 \mathrm{f}_{\mathrm{y}}=0.6 * 250=150 \mathrm{~N} / \mathrm{mm}^{2}$ (for stiffened compression elements) but according to clause 6.2 of [17].

To find effective design width

$\left(\frac{w}{t}\right) \lim =\frac{446}{\sqrt{f}}$

(Clause 5.2.1.1 of [17])

Where $\mathrm{w}=$ width of the flange; $\mathrm{t}=$ thickness of flange.

$\left(\frac{w}{t}\right) \lim =\frac{446}{\sqrt{150}}=39.268$

$\mathrm{w} / \mathrm{t}=60 / 2=30<39.268$

Hence $b=w=60 \mathrm{~mm}$.

Design for edge/lip stiffener.

According to clause 5.2.2 of [17]

The edge stiffener must have minimum moment of inertia equal to

$I_{\min }=1.83 t^{4} \sqrt{\left[\left(\frac{w}{t}\right)^{2}-\frac{27590}{f_{y}}\right]}>9.2 t^{4}$

Where the stiffener lip consists of a simple lip bent at right angel to stiffened element, the required overall depth $d_{\text {min }}$ of such lip is

$d_{\min }=2.8 t \sqrt[6]{\left(\frac{w}{t}\right)^{2}-\frac{27590}{f_{y}}}$

Hence

$I_{\min }=1.832^{4} \sqrt{\left[\left(\frac{60}{2}\right)^{2}-\frac{27590}{250}\right]}>9.2 * 2^{4}$

$I_{\min }=822.8 \mathrm{~mm}^{4}>148 \mathrm{~mm}^{4}$ 
$\mathrm{d}_{\min }=2.8 * 2 \sqrt[6]{\left(\frac{60}{2}\right)^{2}-\frac{27590}{250}}=17 \mathrm{~mm}$

$\mathrm{d}=\sqrt[3]{\mathrm{I}_{\min } * 12}$

$\mathrm{d}=\sqrt[3]{823 * 12}=22 \mathrm{~mm}$

$\mathrm{d}=25 \mathrm{~mm}$

Sectional properties.

$\mathrm{I}_{\mathrm{xx}}=1.9215 \times 10^{6} \mathrm{~mm}^{4}$

$M=\frac{I x x}{y} \times f_{y}$

Where $\mathrm{I}_{\mathrm{xx}}=$ moment of inertia of section horizontal axis passing through centroid of the section.

$\mathrm{Y}=$ distance of extreme fiber in compression from neutral axis.

$\mathrm{M}=\frac{1.9215 * 10^{\wedge} 6}{75} \times 150=3.843 \mathrm{kN}-\mathrm{m}$

For beam under single point load $\mathrm{p}=\frac{4 \mathrm{M}}{\mathrm{l}}$

$\mathrm{p}=\frac{4 * 1.94}{1}=15.372 \mathrm{kN}=1.54 \mathrm{~T}$

\subsection{Analysis of beam sectional profile ' $A$ ' for moment carrying capacity}

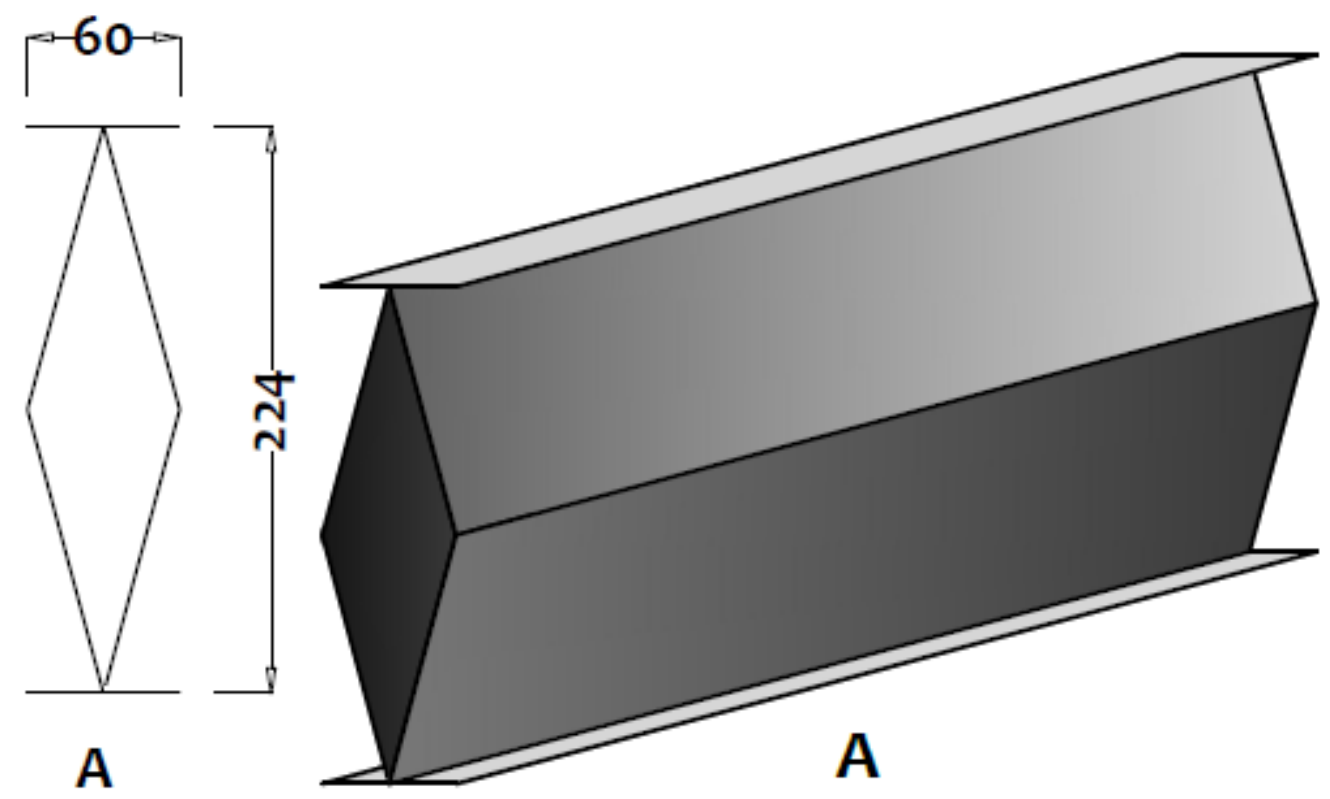

Fig. 6: Sectional Profile 'A'

Basic design stress $\mathrm{f}=0.6 \mathrm{f}_{\mathrm{y}}=0.6 * 250=150 \mathrm{~N} / \mathrm{mm}^{2}$ (for stiffened compression elements) but according to clause 6.2 of [17].

Allowable compression stress in unstiffened element is (in S.I. units)

For

$\frac{\mathrm{w}}{\mathrm{t}} \leq \frac{165}{\sqrt{\mathrm{f}_{\mathrm{y}}}}$

$\mathrm{f}_{\mathrm{c}}=0.6 \sqrt{\mathrm{f}_{\mathrm{y}}}$

For 
$\frac{375}{\sqrt{f_{y}}}>\frac{w}{t}>\frac{165}{\sqrt{f_{y}}}$

$f_{c}=f_{y}\left[0.767-10^{\wedge}-3\left(\frac{w}{t}\right) \sqrt{ } f_{y}\right]$

For

$25>\mathrm{w} / \mathrm{t}>375 / \sqrt{\mathrm{f}_{\mathrm{y}}}$

$f_{c}=54200 /\left(\frac{w}{t}\right)^{2}$

For

$60>\mathrm{w} / \mathrm{t}>25$

$\mathrm{f}_{\mathrm{c}}=134-1.93\left(\frac{\mathrm{w}}{\mathrm{t}}\right)$

Where $\mathrm{w}=$ width of the flange; $\mathrm{t}=$ thickness of the flange.

$\mathrm{f}_{\mathrm{y}}=$ yield stress. $\mathrm{f}_{\mathrm{c}}=$ allowable compressive stress.

Hence from the above clause

$\frac{30}{2} \leq \frac{165}{\sqrt{250}}=15>10.43$

$\frac{375}{\sqrt{f_{y}}}>\frac{w}{t}>\frac{165}{\sqrt{ } f_{y}}$

$\frac{375}{\sqrt{250}}>\frac{30}{2}>\frac{165}{\sqrt{250}}=23.717>15>10.435$.

Hence allowable compressive stress is given by

$f_{c}=f_{y}\left[0.767-10^{-3}\left(\frac{w}{t}\right) \sqrt{f_{y}}\right]$

$\mathrm{f}_{\mathrm{c}=} 250\left[0.767-10^{-3}\left(\frac{30}{2}\right) \sqrt{250}\right]=132.46 \mathrm{~N} / \mathrm{mm}^{2}$

To find effective design width

$\left(\frac{w}{t}\right) \lim =\frac{446}{\sqrt{f}}$

(Clause 5.2.1.1 of [17])

Where $\mathrm{w}=$ width of the flange; $\mathrm{t}=$ thickness of flange.

$(\mathrm{w} / \mathrm{t})_{\lim }$

$\left(\frac{w}{t}\right) \lim =\frac{446}{\sqrt{150}}=36.4$

$\mathrm{w} / \mathrm{t}=30 / 2=15<36.415$

Hence

$\mathrm{b}=\mathrm{w}=30 \mathrm{~mm}$.

Sectional properties. 
$\mathrm{I}_{\mathrm{xx}}=3.02 \times 10^{6} \mathrm{~mm}^{4}$

$M=\frac{I x x}{y} \times f_{y}$

Where $\mathrm{I}_{\mathrm{xx}}=$ moment of inertia of section horizontal axis passing through centroid of the section. $\mathrm{Y}=$ distance of extreme fiber in compression from neutral axis.

$\mathrm{M}=\frac{3.02 * 10^{\wedge} 6}{105} \times 132.46=3.81 \mathrm{kN}-\mathrm{m}$

For beam under single point load $\mathrm{p}=\frac{4 \mathrm{M}}{\mathrm{l}}$

$\mathrm{p}=\frac{4 * 3.81}{1}=15.4 \mathrm{kN}=1.54 \mathrm{~T}$

\subsection{Analysis of beam sectional profile ' $B$ ' for moment carrying capacity}

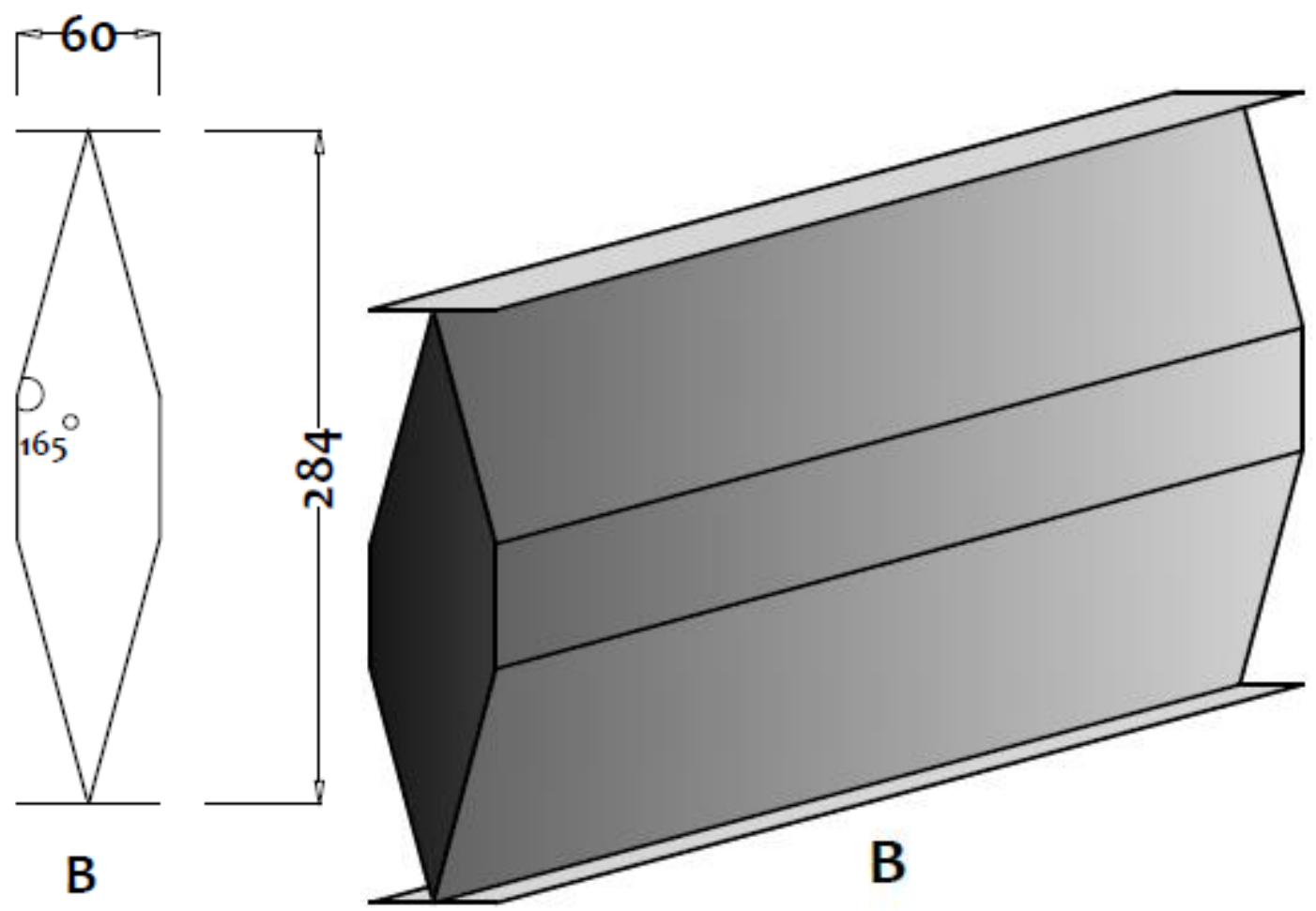

Fig. 7: Sectional Profile 'B'

Basic design stress $\mathrm{f}=0.6 \mathrm{f}_{\mathrm{y}}=0.6 * 250=150 \mathrm{~N} / \mathrm{mm}^{2}$ (for stiffened compression elements) but according to clause 6.2 of [17].

Allowable compression stress in unstiffened element is (in S.I. units)

For

$\frac{w}{t} \leq \frac{165}{\sqrt{f_{y}}}$

$\mathrm{f}_{\mathrm{c}}=0.6 \sqrt{\mathrm{f}_{\mathrm{y}}}$

For

$\frac{375}{\sqrt{f_{y}}}>\frac{w}{t}>\frac{165}{\sqrt{f_{y}}}$

$f_{c=} f_{y}\left[0.767-10^{\wedge}-3\left(\frac{w}{t}\right) \sqrt{ } f_{y}\right]$

For 
$25>\mathrm{w} / \mathrm{t}>375 / \sqrt{\mathrm{f}_{\mathrm{y}}}$

$\mathrm{f}_{\mathrm{c}}=54200 /\left(\frac{\mathrm{w}}{\mathrm{t}}\right)^{2}$

For

$60>\mathrm{w} / \mathrm{t}>25$

$\mathrm{f}_{\mathrm{c}}=134-1.93\left(\frac{\mathrm{w}}{\mathrm{t}}\right)$

Where $\mathrm{w}=$ width of the flange; $\mathrm{t}=$ thickness of the flange.

$f_{y}=$ yield stress. $f_{c}=$ allowable compressive stress.

Hence from the above clause

$\frac{30}{2} \leq \frac{165}{\sqrt{250}}=15>10.43$

$\frac{375}{\sqrt{f_{y}}}>\frac{w}{t}>\frac{165}{\sqrt{f_{y}}}$

$\frac{375}{\sqrt{250}}>\frac{30}{2}>\frac{\mathbf{1 6 5}}{\sqrt{250}}=23.717>15>10.435$.

Hence allowable compressive stress is given by

$f_{c=} f_{y}\left[0.767-10^{-3}\left(\frac{w}{t}\right) \sqrt{f_{y}}\right]$

$\mathrm{f}_{\mathrm{c}=} 250\left[0.767-10^{-3}\left(\frac{30}{2}\right) \sqrt{250}\right]=132.46 \mathrm{~N} / \mathrm{mm}^{2}$

To find effective design width

$\left(\frac{w}{t}\right) \lim =\frac{446}{\sqrt{f}}$

(Clause 5.2.1.1 of [17])

Where $\mathrm{w}=$ width of the flange; $\mathrm{t}=$ thickness of flange.

$(w / t)_{\lim }$

$\left(\frac{\mathrm{w}}{\mathrm{t}}\right) \lim =\frac{446}{\sqrt{150}}=36.4$

$w / t=30 / 2=15<36.415$

Hence

$\mathrm{b}=\mathrm{w}=30 \mathrm{~mm}$.

Sectional properties.

$\mathrm{I}_{\mathrm{xx}}=6.372 \times 10^{6} \mathrm{~mm}^{4}$

$M=\frac{I x x}{y} \times f_{y}$

Where $\mathrm{I}_{\mathrm{xx}}=$ moment of inertia of section horizontal axis passing through centroid of the section. $\mathrm{Y}=$ distance of extreme fiber in compression from neutral axis. 
$M=\frac{6.372 * 10^{\wedge} 6}{142} \times 132.46=5.944 k N-m$

For beam under single point load $p=\frac{4 M}{l}$

$p=\frac{4 * 5.944}{1}=23.776 k N=2.4 T$

\subsection{Analysis of beam sectional profile ' $C$ ' for moment carrying capacity}

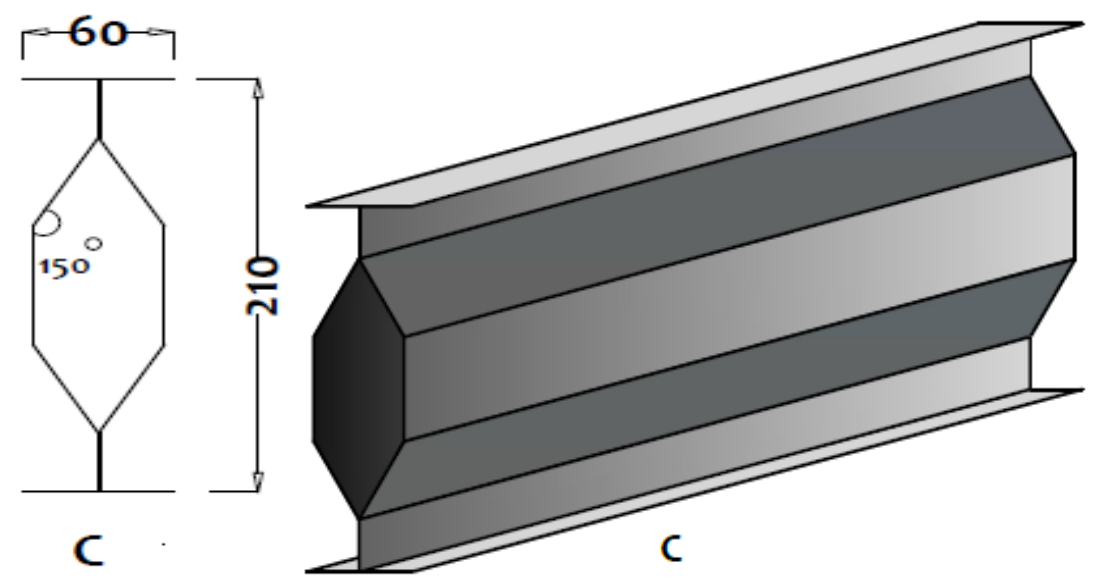

Fig. 8: Sectional Profile ' $C$ '

Basic design stress $\mathrm{f}=0.6 \mathrm{f}_{\mathrm{y}}=0.6 * 250=150 \mathrm{~N} / \mathrm{mm}^{2}$ (for stiffened compression elements) but according to clause 6.2 of [17].

Allowable compression stress in unstiffened element is (in S.I. units)

For

$\frac{w}{t} \leq \frac{165}{\sqrt{f_{y}}}$

$f_{c}=0.6 \sqrt{ } f_{y}$

For

$\frac{375}{\sqrt{f_{y}}}>\frac{w}{t}>\frac{165}{\sqrt{f_{y}}}$

$f_{c=} f_{y\left[0.767-10^{\wedge}-3\left(\frac{w}{t}\right) \sqrt{ } f_{y}\right]}$

For

$25>w / t>375 / \sqrt{ } f_{y}$

$f_{c}=54200 /\left(\frac{w}{t}\right)^{2}$

For

$60>w / t>25$

$f_{c}=134-1.93\left(\frac{w}{t}\right)$

Where $\mathrm{w}=$ width of the flange; $\mathrm{t}=$ thickness of the flange.

$\mathrm{f}_{\mathrm{y}}=$ yield stress. $\mathrm{f}_{\mathrm{c}}=$ allowable compressive stress. 
Hence from the above clause

$\frac{30}{2} \leq \frac{165}{\sqrt{250}}=15>10.43$

$\frac{375}{\sqrt{f_{y}}}>\frac{w}{t}>\frac{165}{\sqrt{f_{y}}}$

$\frac{375}{\sqrt{250}}>\frac{30}{2}>\frac{165}{\sqrt{250}}=23.717>15>10.435$.

Hence allowable compressive stress is given by

$f_{c}=f_{y}\left[0.767-10^{-3}\left(\frac{w}{t}\right) \sqrt{f_{y}}\right]$

$\mathrm{f}_{\mathrm{c}=} 250\left[0.767-10^{-3}\left(\frac{30}{2}\right) \sqrt{250}\right]=132.46 \mathrm{~N} / \mathrm{mm}^{2}$

To find effective design width

$\left(\frac{w}{t}\right) \lim =\frac{446}{\sqrt{f}}$

(Clause 5.2.1.1 of [17])

Where $\mathrm{w}=$ width of the flange; $\mathrm{t}=$ thickness of flange.

$(\mathrm{w} / \mathrm{t})_{\lim }$

$\left(\frac{\mathrm{w}}{\mathrm{t}}\right) \lim =\frac{446}{\sqrt{150}}=36.4$

$\mathrm{w} / \mathrm{t}=30 / 2=15<36.415$

Hence

$\mathrm{b}=\mathrm{w}=30 \mathrm{~mm}$.

Sectional properties.

$\mathrm{I}_{\mathrm{xx}}=3.45 \times 10^{6} \mathrm{~mm}^{4}$

$M=\frac{\mathrm{Ixx}}{\mathrm{y}} \times \mathrm{f}_{\mathrm{y}}$

Where $\mathrm{I}_{\mathrm{xx}}=$ moment of inertia of section horizontal axis passing through centroid of the section. $\mathrm{Y}=$ distance of extreme fiber in compression from neutral axis.

$\mathrm{M}=\frac{3.45 * 10^{\wedge} 6}{112} \times 132.46=4.08 \mathrm{kN}-\mathrm{m}$

For beam under single point load $\mathrm{p}=\frac{4 \mathrm{M}}{\mathrm{l}}$

$\mathrm{p}=\frac{4 * 4.08}{1}=16.32 \mathrm{kN}=1.63 \mathrm{~T}$

\section{Summary of results}

It is interesting to express the results in a tabular form for interpretation. The theoretical load carrying capacities of the innovative sections under flexure are in the consolidated form given in Table 1. 
Table 1: Summary of Results

\begin{tabular}{lcll}
\hline Sectional Profiles & Weight in $\mathrm{kg} / \mathrm{m}$ & $\mathrm{Z}\left(10^{4} \mathrm{~mm}^{3}\right)$ & Load Carrying Capacity $(\mathrm{kN})$ \\
\hline CWOES & 9.45 & 2.55 & 7.76 \\
CWES & 11.02 & 2.55 & 15.4 \\
Sectional profile 'A' & 9.45 & 3.17 & 15.4 \\
Sectional profile 'B' & 13.4 & 4.48 & 24 \\
Sectional profile 'C' & 10.23 & 3.112 & 16.3 \\
\hline
\end{tabular}

The decreasing load carrying capacity order is given below

$($ Sectional profile $\mathrm{B})>($ Sectional profile $\mathrm{C})>($ Sectional profile $\mathrm{A})=(\mathrm{CWES})>(\mathrm{CWOES})$

\section{Conclusions}

The innovative sections governed by specific geometric shapes have shown increased load carrying capacities than the conventional shapes. The innovative sections due to their geometry will have increased resistance against web buckling. Based on the theoretical analysis, following conclusions are drawn.

- The theoretical load carrying capacities under flexure works out $7.76 \mathrm{kN}$ for the shape CWOES, $15.4 \mathrm{kN}$ for the shape CWES, $15.4 \mathrm{kN}$ for the shape Sectional profile 'A', $24 \mathrm{kN}$ for the shape Sectional profile 'B' and $16.3 \mathrm{kN}$ for the shape Sectional profile ' $C$ '.

- $\quad$ From theoretical, investigation the decreasing load carrying capacity order is given below. $($ Sectional profile $\mathrm{B})>($ Sectional profile $\mathrm{C})>($ Sectional profile $\mathrm{A})=(\mathrm{CWES})>(\mathrm{CWOES})$

- Even though Sectional profile 'A' and CWES has same load carrying capacity but Sectional profile 'A' is lighter by $1.57 \mathrm{~kg} / \mathrm{m}$ which leads to $14.25 \%$ reduction in weight.

\section{Acknowledgements}

The authors would like to thank Dr. N. Subramanian, Maryland (USA), Dr. M. Kalgal, Bangalore (India) \& Dr. C. Sashidhar, Anantapur (India) for their valuable suggestions and information regarding this study.

\section{References}

[1] Kalavagunta S, Naganathan S et al. (2012). Cold formed steel in construction: A review of research, challenges and opportunities, ASEASEC-1, Perth, 359-363.

[2] I.S. 811 (1987) Indian Standard Specification for Cold- Formed Light Gauge Structural Steel Sections, Bureau of Indian Standards, New Delhi. India.

[3] American Iron and Steel Institute, (2007). AISI S100 North American specification for the design of cold-formed steel structural members, Washington, DC.

[4] Macdonald M, Heiyantuduwa M A et al. (2008). Recent development in the design of cold-formed steelmembers, Thin-Walled Structures, vol 46(7-9), 1047-1053. http://dx.doi.org/10.1016/j.tws.2008.01.039.

[5] Schafer B W and Pekoz T (1998). Direct strength prediction of cold-formed steel members using numerical elastic buckling solutions, Thinwalled Structures, vol 47, 193-210

[6] Haidarali M R and Nethercot D A (2012). Local and distortional buckling of cold-formed steel beams with edge-stiffened flanges, Journal of Constructional Steel Research, vol 73, 31-42 http://dx.doi.org/10.1016/j.jcsr.2012.01.006.

[7] Cheng S, Kim B et al. (2013). Lateral torsional buckling of cold-formed channel sections subject to combined compression and bending, Journal of Constructional Steel Research, vol 80, 174-180. http://dx.doi.org/10.1016/j.jcsr.2012.07.026.

[8] Yu C, and Schafer B W, (2003). Local buckling tests on cold-formed steel beams, Journal of Structural Engineering, ASCE, vol 129(12), 1596-1606. http://dx.doi.org/10.1061/(ASCE)0733-9445(2003)129:12(1596).

[9] Yu C and Schafer B W (2006). Distortional buckling tests on cold-formed steel beams, Journal of Structural Engineering, ASCE, vol 132(4), 515-528. http://dx.doi.org/10.1061/(ASCE)0733-9445(2006)132:4(515).

[10] Lee J and Kim S E (2002). Lateral buckling analysis of thin-walled laminated channel-section beams, Composite Structures, vol 56(4), 391399. http://dx.doi.org/10.1016/S0263-8223(02)00022-3.

[11] Seah L K and Khong P W (1990). Lateral-torsional buckling of channel beams, Journal Construction Steel Research, vol 17(4), 265-282. http://dx.doi.org/10.1016/0143-974X(90)90076-S.

[12] Li L Y (2004). Lateral-torsion buckling of cold-formed zed-purlins partial-laterally restrained by metal sheeting, Thin-walled Structures, vol 42(7), 995-1011. http://dx.doi.org/10.1016/j.tws.2004.03.005.

[13] Schardt R (1994). Lateral torsional and distortional buckling of channel and hat-sections. Journal Construction Steel Research, vol 31(2/3), 243-265. http://dx.doi.org/10.1016/0143-974X(94)90012-4.

[14] Hancock G J, Murray T M et al. (2001). Cold-formed Steel Structures to the AISI Specification, Marcel Dekker, Inc. http://dx.doi.org/10.1201/9780203907986.

[15] Von Karman T, Sechler E E, et al. (1932). The strength of thin plates in compression, Transactions ASME, vol 54, APM 5405, 53-57.

[16] M. Adil Dar, Deepankar K. Ashish and A.R. Dar (2014). A Study On Cold Formed Steel Beams- A Review. 3(3) Sep-Nov, 2014 Print ISSN 2278-7887, E-ISSN 2320-2343, pp.34-40

[17] Winter G, (1947). Strength of thin steel compression flanges, Transactions of ASCE, vol 112, Paper no. 2305, 527.

[18] I.S. 801 (1975) Indian Standard Code of Practice for Use of Cold-Formed Light Gauge Steel Structural Members in General Building Construction, Bureau of Indian Standards, New Delhi. India. 